\title{
COMPARAÇÃO ENTRE OS MÉTODOS GUT E FMEA - ESTUDO DE CASO
}

\author{
R. A. LEITÃo \\ Engeheira Civil \\ PUCRS \\ Rio Grande do Sul; Brasil \\ e-mail: rafaela.leitao@acadpucrs.br
}

\author{
A. B. ROHDEN \\ Professor \\ PUCRS e FURB \\ Rio Grande do Sul; Brasil \\ e-mail: abrcivil@gmail.com
}

\section{RESUMO}

Considerando a importância de se realizar vistorias preventivas nas edificações, de forma a verificar as anomalias e falhas que com o passar dos anos possam comprometer o bom desempenho dos seus sistemas construtivos. O presente trabalho tem como objetivo verificar e avaliar a ordem de criticidade das anomalias e falhas encontradas em alguns sistemas construtivos de uma edificação. Utilizando uma lista de verificações elaboradas com base em uma lista existente, e através da realização de uma vistoria seguindo as instruções técnicas da Norma de Inspeção Predial Nacional do Instituto Brasileiro de Avaliação e Perícias - IBAPE comparou-se a utilização dos métodos GUT (ferramenta que relaciona Gravidade, Urgência e Tendência) e FMEA (Análise de Modos e Efeitos de Falha Potencial), na classificação dos graus de riscos das anomalias e falhas encontradas nos sistemas construtivos deste prédio.

Palavras-chave: inspeção predial, GUT, FMEA.

\section{ABSTRACT}

Considering the importance of carrying out preventive inspections in buildings, in order to check anomalies and failures that, over the years, may compromise the good performance of their construction systems. This work aims to verify and evaluate the criticality order of anomalies and failures found in some construction systems of a building. Using a list of checks prepared based on an existing list, and by conducting an inspection following the technical instructions of the National Building Inspection Standard of the Brazilian Institute of Assessment and Expertise - IBAPE, the use of GUT methods was compared. relates Gravity, Urgency and Tendency) and FMEA (Analysis of Potential Failure Modes and Effects), in the classification of the degrees of risk of anomalies and failures found in the building systems of this building.

Keywords: building inspection, GUT, FMEA.

\section{INSTRUÇÕES GERAIS}

As edificações no decorrer de sua vida útil sofrem desgastes temporais ou provenientes do uso para a qual foram projetadas, e também padecem por falhas decorrentes de sua construção ou por falta de manutenção predial e intervenções preventivas, podendo por estes motivos ocasionar acidentes que resultam em perda de vidas e danos financeiros. Quedas de marquises e desabamentos de prédios, como o do Edifício Santa Fé, ocorrido em Capão da Canoa no ano de 2009 , resultando no óbito de quatro pessoas, chamam a atenção para a necessidade de se realizar um trabalho técnico, que é a Inspeção Predial ou Vistoria do Check-Up das Edificações (IBAPE, 2012).

Segundo Gomide (2006) assim como o corpo humano, os edifícios devem com regularidade passar por check-ups, que indicarão o "tratamento predial", neste caso, as manutenções necessárias para que o prédio mantenha suas características e durabilidade. Este check-up tem a finalidade de determinar as "doenças", ou seja, anomalias e falhas decorrentes de uso, operação e manutenção as quais acometem a qualidade da edificação.

A Norma de Inspeção Predial do IBAPE define a Inspeção Predial como "A análise isolada ou combinada das condições técnicas, de uso e de manutenção da edificação”. A NBR 5674 (ABNT, 2012), estabelece que periodicamente, conforme 
manual elaborado de acordo com a NBR 14037 (ABNT, 2011) e programa de manutenção de cada edificação, devem realizar inspeções. Os sistemas e elementos construtivos requerem atividades de manutenção durante sua vida útil, assegurando bons níveis de desempenho e segurança primeiro previstos em projeto, de forma a atender as necessidades dos usuários dessas edificações.

No Rio Grande do Sul e no país, municípios instituíram legislações com vistas a garantir que periodicamente sejam feitas inspeções nas edificações para verificar suas condições de segurança ou estabilidade estrutural. Isto de certa forma revela maior preocupação com a importância das Inspeções Periódicas, como forma de prevenir a ocorrência de acidentes ou colapso da estrutura, bem como a indicação das manutenções e correções necessárias, contudo ainda é bastante reduzido o número de municípios que possuem legislações para tal, principalmente as cidades maiores, as quais possuem edifícios e prédios de maior porte. A Inspeção Predial ainda é vista como um gasto desnecessário pelos síndicos e gestores dos prédios, bem como a manutenção preventiva, a cultura ainda difundida é a de procurar ações de manutenção somente quando iniciam a ocorrência das anomalias (IBAPE, 2012). A Inspeção Predial busca prevenir e diminui os riscos de acidentes prediais e auxilia o plano de manutenção.

O presente trabalho teve por objetivo geral a comparação entre o método técnico de gerenciamento de riscos GUT Gravidade, Urgência e Tendência e Análise de Modos e Efeitos de Falhas Potenciais - FMEA para apuração da ordem de prioridades quanto ao grau de risco e intensidade das anomalias e falhas encontradas nos sistemas construtivos de estruturas, prevenção contra incêndio e revestimentos internos, através da realização de uma vistoria de inspeção predial, conforme as instruções técnicas da Norma de Inspeção Predial Nacional do Instituto Brasileiro de Avaliações e Perícias - IBAPE, no prédio de um órgão público em Porto Alegre, sendo utilizada uma lista de verificações baseada no modelo desenvolvido por Verzola (2014). Não serão indicadas no presente trabalho quais as ações corretivas deverão ser realizadas nos sistemas que apresentaram problemas.

\section{INSPEÇÃO PREDIAL}

A Inspeção Predial passou a ser difundida no Brasil, no ano de 1999, durante a realização do X Congresso Brasileiro de Avaliações e Perícias de Engenharia - COBREAP, com a apresentação do trabalho técnico “A Inspeção Predial deve ser periódica e obrigatória?" que teve o objetivo de destacar a importância de se preservar a segurança das edificações pela manutenção. Isto levou para o aprofundamento de estudos relacionados ao tema, com a elaboração da primeira norma de inspeção predial pelo IBAPE/SP no ano de 2001.

Conforme Neves (2009) na prática, a Inspeção Predial caracteriza-se por uma "vistoria para avaliar os estados de conformidade de uma edificação, mediante aspectos de desempenho, exposição ambiental, utilização e operação, observado sempre às expectativas dos usuários". Verzola (2014) destaca a importância da Inspeção Predial para garantia da segurança e habitabilidade das construções, contudo, frequentemente a atenção dos pesquisadores é atraída para os sistemas de infraestrutura civil, como pontes, rodovias e túneis com relação à análise de condições de uso e manutenções.

Em outros países, como por exemplo, Canadá e Estados Unidos, a realização de Inspeções Prediais é atividade rotineira, sendo obrigatório anexar o laudo nos contratos de transações imobiliárias e nos quadros de avisos de prédios públicos, ser fixado o Certificado de Inspeção Predial (GOMIDE, 2006).

Verzola (2014) salienta também, que no Brasil a Inspeção Predial não possui publicada uma norma específica elaborada pela ABNT, os profissionais orientam-se por fragmentos de normas já publicadas, como: a NBR 13752 (ABNT, 1996) perícias de engenharia na construção civil; a NBR 5674 (ABNT, 2012) - requisitos para o sistema de gestão da manutenção; a NBR 14037 (ABNT, 2011) - diretrizes para elaboração de manuais de uso e operação das edificações, a NBR 15575 (ABNT, 2013) - edificações habitacionais, desempenho e seguindo as instruções técnicas da Norma de Inspeção Predial do IBAPE (2012). A Associação Brasileira de Normas Técnicas (ABNT) possui uma comissão de estudos para elaboração de uma norma de inspeção em edificações, a qual teve seu texto aprovado para encaminhamento a consulta nacional.

Nascimento (2015) destaca que "toda edificação, para manter um funcionamento satisfatório, deve ser submetida a uma rotina de inspeção e manutenção da edificação visando orientar a manutenção e a qualidade predial total". Cabe esclarecer que a Inspeção Predial não é a manutenção da edificação e sim uma das ferramentas que auxilia a elaboração ou revisão do plano de manutenção e na gestão predial, sendo uma vistoria que possui natureza visual, não sendo empregados ensaios, os quais se assim necessários deverão ser indicados no laudo a ser elaborado (IBAPE, 2012). Angeloni (2011) enfatiza que a Inspeção Predial "visa uma boa manutenção na edificação, priorizando as anomalias e falhas e realizando 
recomendações aos usuários”. A manutenção, conforme preconiza a NRB 5674 (ABNT, 2012), é o conjunto de atividades a serem realizadas ao longo da vida total da edificação para conservar ou recuperar a sua capacidade funcional e de seus sistemas constituintes de atender as necessidades e segurança dos seus usuários.

Segundo IBAPE (2012) anomalias e falhas são inconformidades que ocasionam perda de desempenho precoce de elementos e sistemas construtivos e diminuição de vida útil de projeto, podendo comprometer os critérios de desempenho, conforme definidos na NBR 15575 (ABNT, 2013). As anomalias são os erros que envolvem projeto, execução, fatores externos e de degradação pelo envelhecimento natural e término de vida útil, podendo ser classificadas em: construtivas, que são as provenientes da própria construção e funcionais, que são provenientes ao uso. As falhas ocorrem em função de procedimentos inadequados de planejamento e execução de manutenção, bem como inadequados procedimentos operacionais e gerenciais.

Na realização da inspeção predial, é feita uma classificação e análise das anomalias e falhas, de acordo com o grau de risco apresentado, provendo direcionar os serviços a serem realizados e a ordem cronológica com que deverão ser executados, fazendo com que sejam planejados os gastos e os serviços racionalizados. Grande parte das anomalias e falhas constatadas através da inspeção predial podem a um curto prazo comprometer o bom funcionamento do edifício e a integridade física dos seus ocupantes (NEVES, 2009).

Para diagnóstico das anomalias ou falhas, é elaborada uma lista de verificação, ou check-list, o qual segundo Angeloni (2011) deve ser o mais detalhado possível, para uma análise mais completa e posterior elaboração do Laudo de Inspeção Predial, documento técnico que deve demonstrar todas as etapas do trabalho e basear conclusão (IBAPE, 2012).

A listagem de verificação ou check-list é o documento no qual o inspetor predial utiliza para anotação dos dados de sua inspeção, sendo comumente utilizada uma planilha que elenca os elementos que deverão serem inspecionados, de forma a facilitar os dados de levantamentos de campo, sendo uma ferramenta de grande utilidade para a Inspeção Predial, segundo Gomide (2006). Conforme Pinheiro (2010) "devem ser elaboradas pelo inspetor engenheiro, de acordo com o uso, localização e tipo de instalações presentes na edificação”.

A Norma do IBAPE sugere o uso de métodos, para determinar quais reparos devem ser feitos com maior urgência, estabelecendo uma ordem de prioridades organizada em ordem decrescente, quanto aos graus de risco e intensidade das anomalias e falhas, sugerindo para isto, utilização de metodologias como GUT (ferramenta de gerenciamento, Gravidade Urgência e Tendência) e Análise de Modo e Efeito de Falha - FMEA. Gomide (2011), também menciona a utilização do Diagrama de Pareto para determinação da ordem de prioridades.

Verzola (2014) propôs uma lista de verificações para inspeção predial, de forma a contemplar a informação sobre a gravidade e urgência das manutenções, através de uma classificação a ser usada no método GUT, que tem a finalidade de diminuir a subjetividade na análise dos dados, e com base nesta lista, identificar as manifestações patológicas mais importantes e ser uma ferramenta possível de ser aplicada em atendimento às leis municipais. Costa (2012) apresentou um estudo de caso de um edifício residencial, onde através da realização de vistoria neste edifício, identificou as principais patologias construtivas e elaborou a matriz GUT dos riscos associados, evidenciando a incidências das referidas patologias, concluindo que alguns reparos deveriam ser realizados de imediato e recomendando que vistorias periódicas sejam realizadas para acompanhar a evolução destas patologias. Thompson Junior (2011) apresentou a inspeção predial de cinco creches na cidade de Içara-SC com levantamento das principais patologias construtivas, identificando e diagnosticando as suas prováveis causas e com isto elaborou a matriz GUT dos danos existentes.

Embora mais utilizada na Engenharia de Produção e Industrial, para a melhoria de produtos e processos, Silva (2013), aplicou em uma inspeção predial a metodologia FMEA para determinação das causas mais incidentes dos problemas encontrados nos sistemas construtivos da edificação de uma instituição de saúde. A Inspeção Predial está inserida no rol da Engenharia Diagnóstica, que conforme Pinheiro (2010) é "um braço da engenharia legal, cujo outro lado é a engenharia de avaliações".

Gomide, Neto e Gulo (2009, p.14) apresentam as seguintes definições (Figura 1):

"Sintomatologia técnica da edificação: constatações e análises dos sintomas e condições físicas das anomalias construtivas e falhas de manutenção; Etiologia técnica da edificação: determinação dos efeitos, origens, causas, mecanismos de ação, agentes e fatores de agravamento das anomalias construtivas e falhas de manutenção; Terapêutica 
da edificação - Estudos das reparações das anomalias construtivas e falhas de manutenção."

Gomide (2009) também enuncia os conceitos de investigação, sendo vistoria a constatação técnica de determinado fato, condição ou direito relativo a uma edificação, mediante verificação in loco, inspeção a análise técnica de fato, condição ou direito relativo a uma edificação, auditoria o atestamento técnico de conformidade de um fato condição ou direito relativo a uma edificação, perícia a determinação da origem, causa e mecanismo de ação de um fato, condição ou direito relativo a uma edificação e consultoria a prescrição técnica a respeito de um fato, condição ou direito relativo a uma edificação.

Segundo Gomide (2006) o enfoque técnico, funcional e de manutenção, leva a uma visão tríplice, conhecida como visão sistêmica tridimensional (Figura 2), sendo o técnico, levantar as anomalias construtivas do prédio, sejam de produtos ou sistemas e a análise de seus desempenhos; o de uso relacionado aos problemas encontrados relativos ao uso incorreto dos sistemas, confiabilidade da segurança, análise de desempenho quanto ao conforto homem/ambiente e o de manutenção, o levantamento das falhas ocasionadas por manutenção incorreta ou pela falta da mesma.

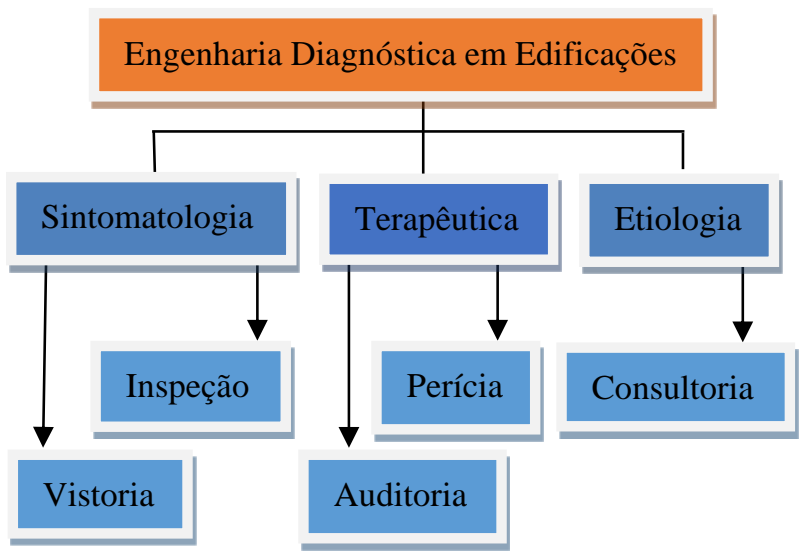

Figura 1: Ferramentas diagnósticas. Fonte: GOMIDE; FAGUNDES NETO; GULO, 2009.

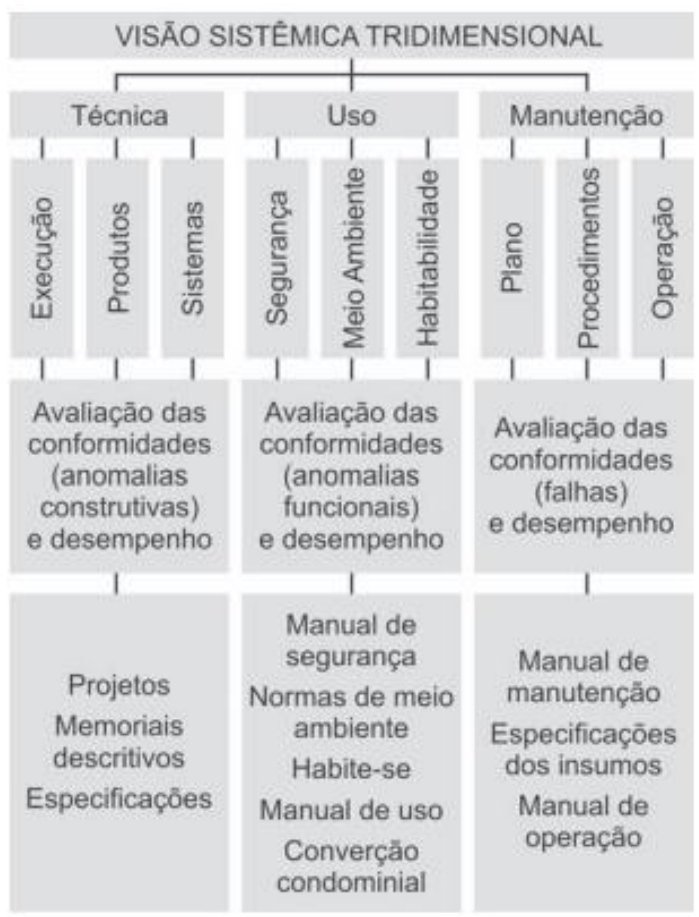

Figura 2: Visão Sistêmica Tridimensional - Fonte: GOMIDE; PUJADAS; FAGUNDES NETO, 2006.

Conforme Pinheiro (2010):

“O que diferencia a Inspeção predial dos outros tipos de vistoria é o foco nesta avaliação tríplice: uso, manutenção e técnica, aumentando a durabilidade e garantindo o desempenho de uma construção e o pleno funcionamento e uso; elabora orientações técnicas quando necessário, classificam os problemas em níveis de criticidade e os organizam em ordem de prioridade. Caracteriza-se por seu caráter multidisciplinar objetivando a prevenção e faz distinção entre plano de manutenção e plano de reparo".

Dentro deste conceito da visão sistêmica tridimensional, da combinação do uso, manutenção e técnica, Angeloni (2011) apresentou um estudo de caso, com a inspeção de casas populares do programa Minha Casa Minha Vida, no município de Jacinto Machado, estado de Santa Catarina, onde analisou as patologias mais frequentes encontradas bem como foram indicadas recomendações técnicas a serem executadas, sugerindo ao agente financeiro a elaboração de um manual de conservação e uso das casas e os prazos de execução das correções, pois os usuários desconheciam sobre as manutenções a serem realizadas nos imóveis. 
Gomide (2006) ainda destaca que a Inspeção Predial deve atender a etapas, e um número mínimo de itens devem ser inspecionados. Alguns outros fatores também devem ser levados em consideração, a documentação que deve ser apresentada, a vistoria que deverá ser realizada, a lista de verificações (check-list) e o laudo de inspeção predial a ser elaborado.

Conforme estabelece a Norma de Inspeção Predial (IBAPE, 2012), devem ser seguidas etapas para realização de uma Inspeção Predial, que envolvem levantamento de dados e documentos da edificação, entrevista com síndico ou gestor para verificar o histórico de intervenções, vistoria dos sistemas para determinação do nível de inspeção, conforme análise das características da edificação e sua complexidade (nível 1,2 ou 3), verificação das deficiências constatadas - anomalias e falhas e classificação do grau de risco das anomalias e falhas (crítico, médio e mínimo), ordenamento de prioridades técnicas, do mais crítico ao menos crítico; recomendações ou orientações técnicas, avaliação de qualidade da manutenção e avaliação do uso da atividade da edificação.

Quanto ao grau de risco, a norma do IBAPE considera como crítico aquele que provoca danos contra a saúde das pessoas e meio ambiente, com perda excessiva de desempenho e funcionalidade, causando possíveis paralisações, aumento excessivo de custo e comprometimento sensível de vida útil; médio é aquele que provoca a perda parcial de desempenho e funcionalidade da edificação, sem prejuízo à operação direta de sistemas e deterioração precoce e mínimo aquele causado por pequenas perdas de desempenho e funcionalidade, principalmente quanto à estética ou atividade programável e planejada, sem incidência ou sem a probabilidade de ocorrência dos riscos críticos e regulares, além de baixo ou nenhum comprometimento do valor imobiliário.

Quanto ao nível de inspeção, a norma do IBAPE considera o nível um para edificações com baixa complexidade técnica, com planos de manutenção muito simples ou inexistentes, para este nível é elaborada por profissional habilitado em uma especialidade; a inspeção de nível dois refere-se a edificações com média complexidade técnica, de manutenção e operação e com sistemas convencionais, edificações com vários pavimentos, com ou sem plano de manutenção, nas quais empresas terceirizadas executam as atividades de manutenção, a inspeção predial nesse nível é elaborada por profissionais habilitados em uma ou mais especialidades; a inspeção nível três diz respeito a edificações com alta complexidade técnica, de manutenção e operação de seus elementos e sistemas construtivos, edificações com vários pavimentos ou com sistemas construtivos com automação, nesse nível é obrigatório plano de manutenção com base na NBR 5674 (ABNT, 2012), possuir profissional habilitado responsável técnico, softwear de gerenciamento, e outras ferramentas de gestão do sistema de manutenção existente. A Inspeção nesse nível é elaborada por profissionais habilitados e de mais de uma especialidade.

A Norma do IBAPE nacional também recomenda a vistoria na inspeção predial de no mínimo, os seguintes sistemas construtivos e seus elementos: estrutura, impermeabilização, instalações hidráulicas e elétricas, revestimentos externos em geral, esquadrias, revestimentos internos, elevadores, climatização, exaustão mecânica, ventilação, coberturas, telhados, combate a incêndio e SPDA. A documentação a ser analisada depende do nível de Inspeção e do tipo do empreendimento, sendo dividido em: documentos administrativos, documentos técnicos e de manutenção e operação (GOMIDE, 2006). A Norma do IBAPE sugere que alguns documentos da edificação, tais como alvarás, projetos, licenciamentos, memoriais, etc, sejam requisitados pelo engenheiro inspetor, conforme a necessidade e o tipo de edificação a ser inspecionada.

Segundo neves (2009), a Inspeção deve ser feita do subsolo até o último pavimento; para o sistema elétrico, deve ser executada do ponto de entrada de energia até as ramificações, inspecionando quadros elétricos, fiações aparentes, etc, os sistemas civis ou hidráulicos devem ser inspecionados todos os elementos visíveis, do último pavimento do prédio ao subsolo.

Todos os locais da edificação devem ser vistoriados, desde as áreas comuns a unidades autônomas, estas últimas somente podem ser efetuadas com a autorização dos proprietários, e acompanhadas por eles ou pessoas autorizadas, podendo comprometer o resultado da inspeção, caso não autorizadas, pois muitas modificações costumam serem feitas pelos proprietários, limitando-se as porções visíveis dos sistemas e elementos. Caso não seja possível, por motivo de condições de segurança de acesso ou algum outro que impeça sua verificação, devem ser mencionados no laudo (Pinheiro, 2010).

Após as etapas cumpridas, deve ser gerado o Laudo de Inspeção Predial, demostrando todas as etapas realizadas na atividade de inspeção e as recomendações a serem adotadas. Este laudo deve conter requisitos mínimos, conforme preconiza a norma de Inspeção Predial do IBAPE. Conforme IBAPE (2012) “o Laudo de Inspeção Predial não é apenas um check-list com fotografias. É um documento que segue diretriz técnica para ser elaborado, a fim de demonstrar todas as etapas do trabalho e fundamentar conclusão". 


\subsection{Método GUT}

Kepner e Tregoe, citados por Verzola (2014), desenvolveram a metodologia GUT que é uma ferramenta para gerenciamento de riscos, que leva em consideração gravidade $(\mathrm{G})$, urgência $(\mathrm{U})$ e tendência $(\mathrm{T})$ dos problemas a serem verificados, esta metodologia, foi publicada em 1977, sob o título Análise de Problema e Tomada de Decisão. Para Gomide (2006), o método GUT, objetiva mensurar a importância de cada falha.

O método GUT constitui-se na avaliação do grau de criticidade de cada aspecto analisado das falhas construtivas para após, efetuar uma interação matemática entre estes aspectos avaliados, de acordo com pesos atribuídos para cada criticidade, obtendo um valor numérico para cada incorreção técnica, desta forma obtendo uma ordem de prioridade das providências para manutenções corretivas ou preventivas. Cada aspecto mostra cinco graus ou níveis de criticidade (ou comprometimento), sendo para cada grau atribuído um peso para os aspectos de gravidade, urgência e tendência dos sistemas inspecionados. Após, o resultado do produto gravidade*urgência*tendência é calculado, definindo a prioridade do problema, elencando-os do mais ao menos urgente. Por fim estes são organizados em uma planilha de prioridades, quanto maior o produto resultante de $\mathrm{G}^{*} \mathrm{U} * \mathrm{~T}$, maior é seu grau de risco e mais rápida deve ser a intervenção para corrigilo (GOMIDE, 2011).

Por gravidade entende-se o nível e intensidade dos riscos que podem trazer aos usuários, ou falta de algum elemento de segurança, urgência o prazo para reparos, considerando os riscos e evolução do problema encontrado e tendência à forma de velocidade da evolução da referida ocorrência. Na Tabela 1 foi apresentado um quadro analítico sugerido por Gomide (2006) para Inspeção Predial dos aspectos de Gravidade, Urgência e Tendência e seus respectivos pesos.

Tabela 1 - Classificação GUT

\begin{tabular}{c|c|c|c|c}
\hline Grau & Peso & Gravidade & Urgência & Tendência \\
\hline Total & 10 & $\begin{array}{c}\text { Risco à vida dos usuários, colapso da edificação, } \\
\text { dano ambiental grave }\end{array}$ & Evento em ocorrência & $\begin{array}{c}\text { Evolução } \\
\text { imediata }\end{array}$ \\
\hline Alta & 8 & $\begin{array}{c}\text { Risco de ferimento aos usuários, avaria não } \\
\text { recuperável na edificação, contaminação localizada }\end{array}$ & $\begin{array}{c}\text { Evento prestes a } \\
\text { ocorrer }\end{array}$ & $\begin{array}{c}\text { Evolução em } \\
\text { curto prazo }\end{array}$ \\
\hline Média & 6 & $\begin{array}{c}\text { Insalubridade aos usuários, deterioração elevada } \\
\text { da edificação, desperdício dos recursos naturais }\end{array}$ & $\begin{array}{c}\text { Evento prognosticado } \\
\text { para breve }\end{array}$ & $\begin{array}{c}\text { Evolução em } \\
\text { médio prazo }\end{array}$ \\
\hline Baixa & 3 & $\begin{array}{c}\text { Incômodo aos usuários, degradação da edificação, } \\
\text { uso não racional dos recursos naturais }\end{array}$ & $\begin{array}{c}\text { Evento prognosticado } \\
\text { para adiante }\end{array}$ & $\begin{array}{c}\text { Evolução em } \\
\text { longo prazo }\end{array}$ \\
\hline Nenhuma & 1 & Depreciação imobiliária & Evento imprevisto & Não evoluir \\
\hline
\end{tabular}

\subsection{Análise dos Modos e Efeitos de Falha Potencial - FMEA}

Análise de Modo e Efeitos de Falha Potencial (FMEA), segundo a NBR 5462 (ABNT, 1994) é um método qualitativo de análise de confiabilidade que envolve o estudo dos modos de falhas que podem existir para cada item, e a determinação dos efeitos de cada modo de falha sobre os outros itens e sobre a função requerida do item.

De acordo com Sakurada (2001) "é uma técnica analítica utilizada como uma maneira de garantir que dentro do possível, os modos potenciais de falha e suas causas/mecanismos tenham sido considerados e localizados", sendo considerada assim como o método GUT, uma ferramenta de gerenciamento de risco. Possibilita melhora no sistema o qual é aplicado, pois detecta os pontos com problemas, fazendo com que sejam relacionadas possíveis falhas em seus elementos ou componentes e estudando as consequências destas no sistema todo. É uma ferramenta utilizada largamente na indústria automobilística e na década de 60 foi amplamente utilizada pela indústria e agências aeroespacial, tendo atribuída sua utilização à primeira viagem tripulada à lua (Kalil, 2011).

O FMEA tem por objetivo identificar, delimitar e descrever as não conformidades (modos da falha) geradas pelo processo e seus efeitos e causas, para através de ações de prevenção poder diminuí-los ou eliminá-los. É recomendado para seu desenvolvimento, o envolvimento de uma equipe de profissionais, para uma melhor análise.

Modo de falha está relacionado ao fato de como um processo pode ser levado a operar de maneira deficiente, a maneiro como o item falha ou deixa de executar sua função e é composto por três elementos: efeito, causa e detecção. Efeitos são as consequências do modo de falha; causa é o que indica a razão da falha ter ocorrido. 
O Manual de Referência Análise de Modo de Falha e Efeitos Potenciais (CHRYSLER, 2008), descreve a severidade como o valor associado para a gravidade da falha. A causa potencial de falha, é definida como o processo poderia permitir que a falha ocorresse, podendo ser uma indicação da fragilidade do projeto, cuja consequência é o modo de falha e a detecção identifica a capacidade de detecção da causa ou modo de falha antes de chegar ao usuário. Detecção é a forma utilizada no controle do processo para evitar as falhas potenciais.

Utiliza-se classificações com pesos para os itens de severidade, ocorrência e detecção, sendo a avaliação de risco determinada pelo número de prioridade risco (NPR), resultado da multiplicação da severidade*ocorrência*detecção. Após, deve ser indicada uma ação corretiva para cada. As Tabelas 2, 3 e 4 apresentam uma classificação dos itens severidade, ocorrência e detecção com os pesos atribuídos para cada um destes itens.

Tabela 2 - Classificação FMEA quanto à Severidade

\begin{tabular}{c|c|c}
\hline Severidade do Efeito & Classificação de Severidade & Efeito \\
\hline Perigoso sem aviso prévio & 10 & Falha em atender a requisitos \\
de segurança e/ou regulatórios
\end{tabular}

Tabela 3 - Classificação FMEA quanto à Ocorrência

\begin{tabular}{c|c}
\hline Probabilidade de falha & Classificação da ocorrência \\
\hline $\begin{array}{c}\text { Muito alta: falha é } \\
\text { praticamente inevitável }\end{array}$ & 10 \\
\hline \multirow{3}{*}{ Alta: falhas repetidas } & 9 \\
\cline { 2 - 2 } & 8 \\
\cline { 2 - 2 } & 7 \\
\cline { 2 - 2 } Moderada: falhas ocasionais & 6 \\
\cline { 2 - 2 } & 5 \\
\cline { 2 - 2 } & 4 \\
\hline Baixa: poucas falhas & 3 \\
\hline Muito baixa: falha improvável & 2 \\
\hline
\end{tabular}

Tabela 4 - Classificação FMEA quanto à

\begin{tabular}{c|c}
\multicolumn{2}{|c}{ Detecção } \\
\hline Detecção & Classificação de Detecção \\
\hline $\begin{array}{c}\text { Praticamente } \\
\text { impossível }\end{array}$ & 10 \\
\hline Muito remota & 9 \\
\hline Remota & 8 \\
\hline Muito Baixa & 7 \\
\hline Baixa & 6 \\
\hline Moderada & 5 \\
\hline Moderadamente \\
alta & 4 \\
\hline Alta & 3 \\
\hline Muito alta & 2 \\
\hline Praticamente certa & 1
\end{tabular}

\section{MÉTODO}

A edificação inspecionada abriga a sede de um órgão público de Porto Alegre, localizado na Avenida Ipiranga (Figura 3). Foi construído na década de 1990 e é composta por 8 pavimentos, 2 subsolos e possui uma área total de $5.484,43 \mathrm{~m}^{2}$, sendo estruturado em concreto armado, com elementos de vedação em alumínio e pele de vidro e pilares revestidos de placas de granito. Possui dois elevadores e sistema de climatização por chillers. A estrutura abriga as repartições responsáveis pelo andamento dos trabalhos deste órgão público e ainda não possui um plano de manutenção. Para os sistemas que requerem manutenções recorrentes, como o sistema de bombas, ar-condicionado, elevadores, limpeza, desinsetização, etc, são licitados contratos com empresas que prestam estes serviços. Algumas manutenções são efetuadas pela equipe do quadro funcional, sendo limitadas a pequenos reparos internos sem grande complexidade. Por se tratar de um órgão público, se necessários reparos de maior porte, abre-se um processo licitatório para contratação de empresa especializada. 
A Inspeção foi realizada a partir de uma lista de verificações baseada na elaborada por Verzola (2014). Primeiramente, as anomalias e falhas foram classificadas quanto ao seu grau de risco, conforme a Norma de Inspeção Predial do IBAPE e após, classificadas de acordo com as técnicas de gerenciamento de riscos das metodologias GUT e FMEA.

Foram escolhidos os subsistemas construtivos de estrutura, revestimentos internos e prevenção contra incêndio, pois nestes se apresentaram anomalias e falhas que breve precisarão de intervenções e manutenções corretivas ou que podem ser corrigidas de imediato, pois requerem ações simples para sua correção. As não conformidades foram classificadas pelo seu grau de risco e deficiência e serão apresentadas em planilhas com a aplicação das ferramentas de classificação de risco pelas metodologias GUT e FMEA. As etapas da execução do trabalho são apresentadas na Figura 4.

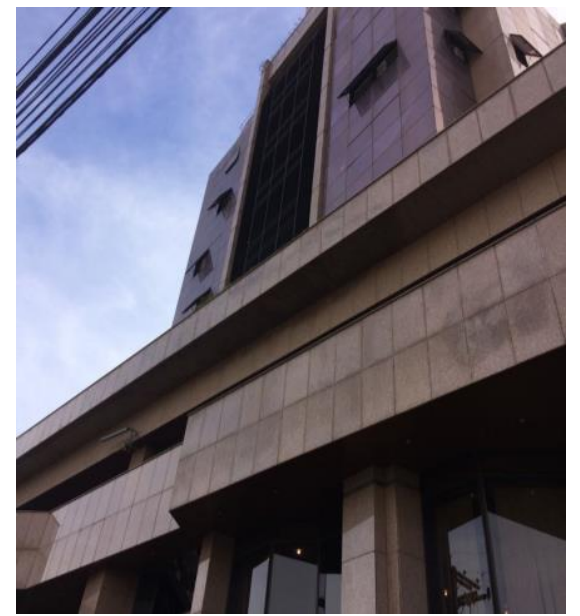

Figura 3 - Vista do Prédio Inspecionado.

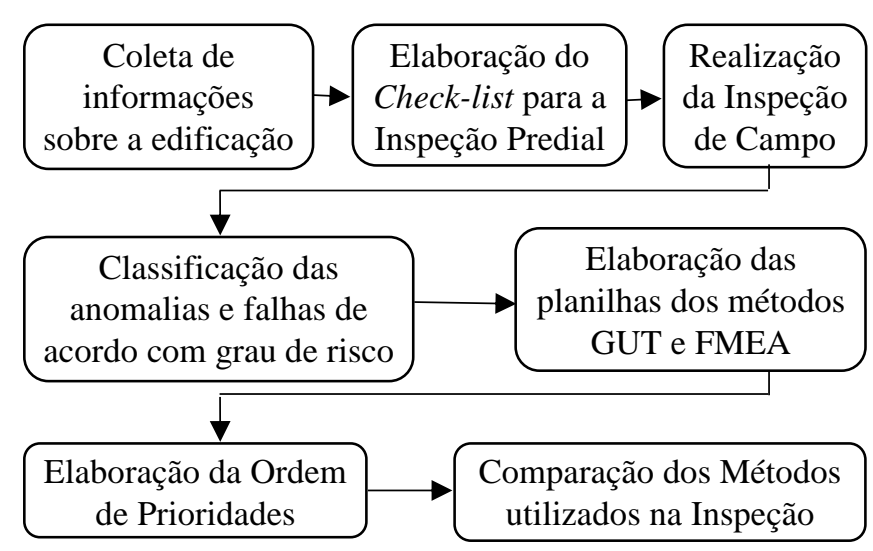

Figura 4 - Fluxograma com as principais etapas do trabalho.

\section{RESULTADOS}

Segundo os critérios da Norma de Inspeção do IBAPE já descritos, a Inspeção é classificada no nível dois, pois a edificação é considerada de média complexidade técnica e não possui plano de manutenção. A vistoria foi realizada no dia 22 de maio de 2017, com a aplicação in-loco da lista de verificações, elaborada a partir do modelo proposto por Verzola (2014). Os sistemas vistoriados (estruturas, prevenção contra incêndios e vedação/ revestimentos) são subdivididos de acordo com os elementos que o compõe, sendo apontadas as características construtivas de cada elemento. Para cada sistema, estão listadas as manifestações patológicas mais comuns, devendo ser marcado sim ou não para a verificação das manifestações observadas. Os itens que não apresentaram anomalias e falhas foram suprimidos da lista original.

As tabelas 2, 3 e 4 apresentam as listas de verificações dos sistemas de elementos estruturais passíveis de verificação visual, prevenção contra incêndio e sistemas de vedação e revestimentos, onde estão indicadas as principais manifestações patológicas encontradas ou inconformidades, e suas classificações quanto ao grau de risco de acordo com a Norma de Inspeção do IBAPE. Nos sistemas de elementos estruturais, as manifestações patológicas referentes à formação de fissuras, exposição da armadura e infiltrações foram classificados como grau de risco críticos, pois entende-se que este tipo de manifestação patológica pode evoluir ocasionando consequências mais sérias para a estrutura em questão; as manifestações de deterioração de materiais/destacamento/desagregação, eflorescência/desenvolvimento de organismos biológicos foram classificadas como graus de risco médios. Nos sistemas de prevenção contra incêndios passíveis de verificação visual, o item obstrução de acesso foi classificado como grau de risco crítico, pois se entende como um risco à segurança dos usuários em caso de ocorrência de algum incêndio na edificação. Os itens degradação/desgaste do material e falha na sinalização foram classificados como graus de risco médio.

Na manifestação indicada na figura 5, observou-se no pavimento superior ao desta, a ocorrência de vibrações ocasionadas pelo schiller do ar condicionado e a umidade advinda de recorrentes vazamentos de água do schiller, onde pode se observar a formação de fissuras, e um local onde a armadura está exposta. Na figura 6 , em uma viga localizada no $2^{\circ}$ pavimento, o qual uma parte deste destina-se a estacionamento de veículos, observou-se a formação de fissuras. Acima deste local, no $3^{\circ}$ pavimento, há um terraço e conforme informações obtidas com os engenheiros da instituição objeto do estudo, não há registros de reparos ou verificações no sistema de impermeabilização. 
A Figura 7 demonstra a manifestação localizada no $2^{\circ}$ subsolo, onde se observa a ocorrência de exposição da armadura, destacamento/desagregação do concreto e também destacamento da pintura de revestimento do forro do $2^{\circ}$ subsolo, possivelmente ocasionado pela ocorrência de umidade advinda do pavimento superior, no qual há um vazamento hidráulico. Neste mesmo local, a umidade ocasionou o surgimento de organismos biológicos (bolor), que além de causar desconforto visual, pode levar a problemas de saúde (Figura 8).

A figura 9 demonstra as paredes e parte da laje localizada no $2^{\circ}$ subsolo com a ocorrência de manifestação de organismos biológicos e a formação de eflorescências. Na figura 10, existe um vazamento hidráulico localizado no $1^{\circ}$ subsolo, onde no pavimento abaixo foram observadas as manifestações patológicas. Na figura 11 observa-se a pintura da parede do $2^{\circ}$ subsolo, com a ocorrência de empolamento (formação de bolhas).

Na Figura 12, localizada no $1^{\circ}$ subsolo, observa-se a existência de dois extintores, porém somente um deles está sinalizado no local. O piso antiderrapante do acesso ao prédio apresenta desgaste, podendo ocasionar acidentes, conforme demonstra a Figura 14. O extintor localizado no $10^{\circ}$ pavimento tem seu acesso obstruído pela deposição de materiais no local onde o mesmo está localizado (Figura 15). O forro de gesso localizado no $2^{\circ}$ pavimento, conforme demostrado na Figura 16 apresenta dano, tendo caído maior parte.

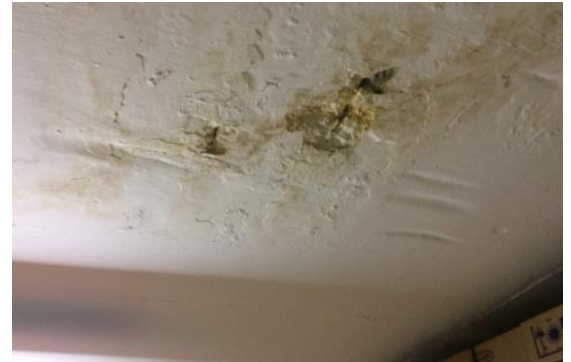

Figuras 5: Vistas da laje do $2^{\circ}$ subsolo com exposição da armadura e formação de fissuras.

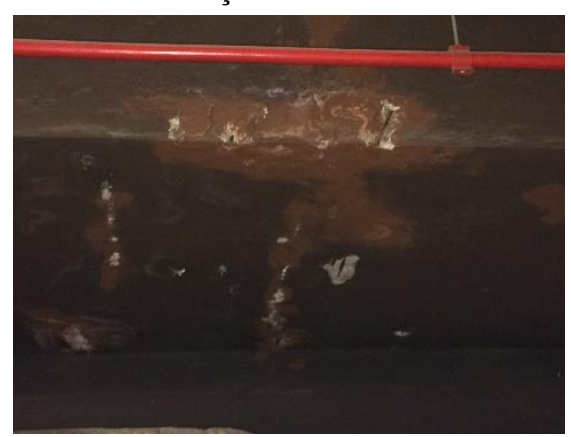

Figura 6: Viga do $2^{\circ}$ pavimento com exposição da armadura e formação de fissuras.

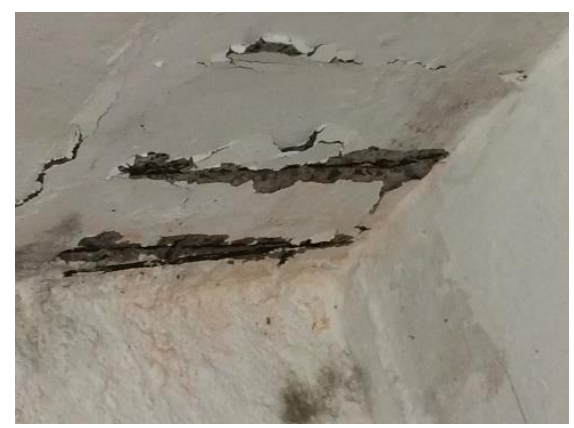

Figura 7: Vistas da Laje do $2^{\circ}$ subsolo exposição da armadura.

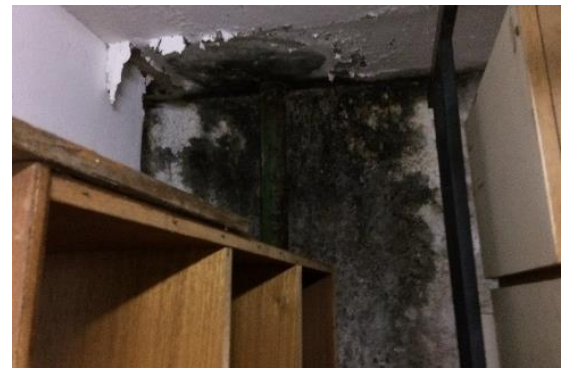

Figura 8: Vista da Laje do $2^{\circ}$ subsolo com eflorescência, desenvolvimento de organismos biológicos

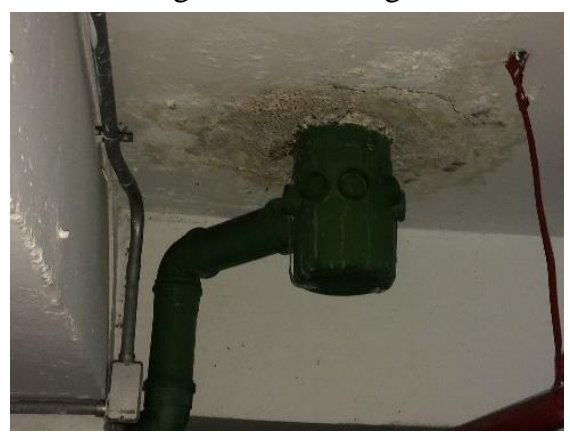

Figura 9: Vista da Laje do $2^{\circ}$ subsolo com eflorescência, desenvolvimento de organismos biológicos

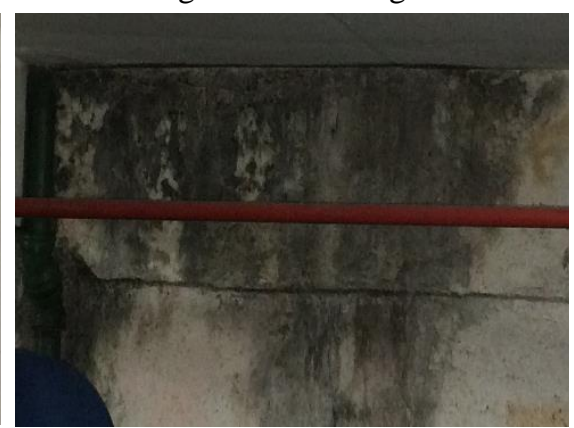

Figuras 10: Vista do piso do $1^{\circ}$ e $2^{\circ}$ subsolo com infiltrações

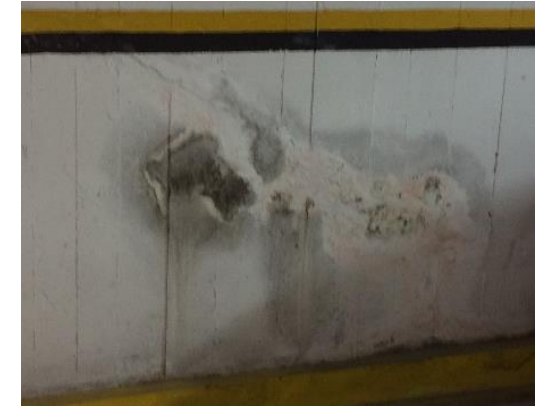

Figuras 11: Deterioração dos materiais, empolamento.

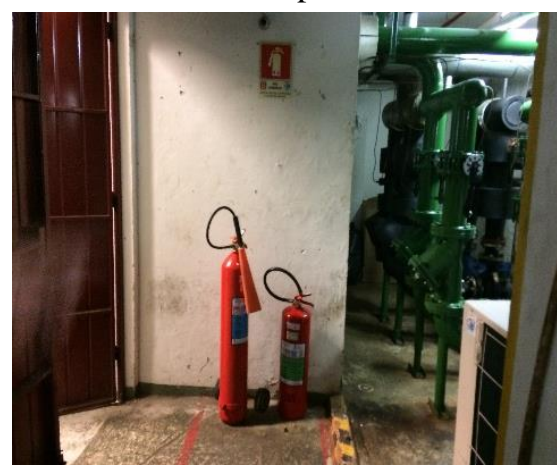

Figuras 12: Falha na sinalização, desgaste do piso antiderrapante

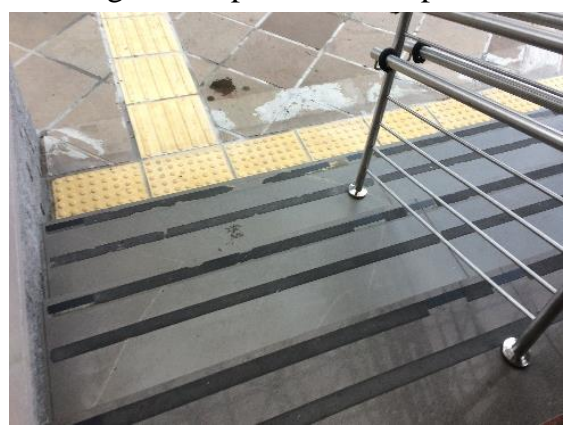

Figuras 13: Falha na sinalização, desgaste do piso antiderrapante 


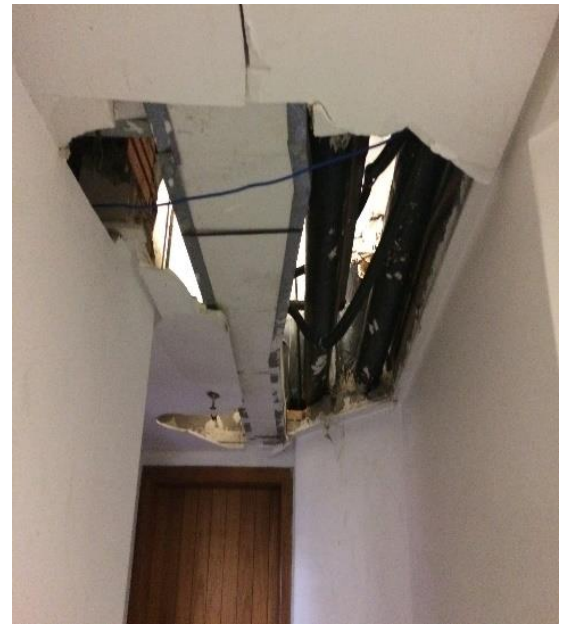

Figura 14: Dano no forro de gesso.

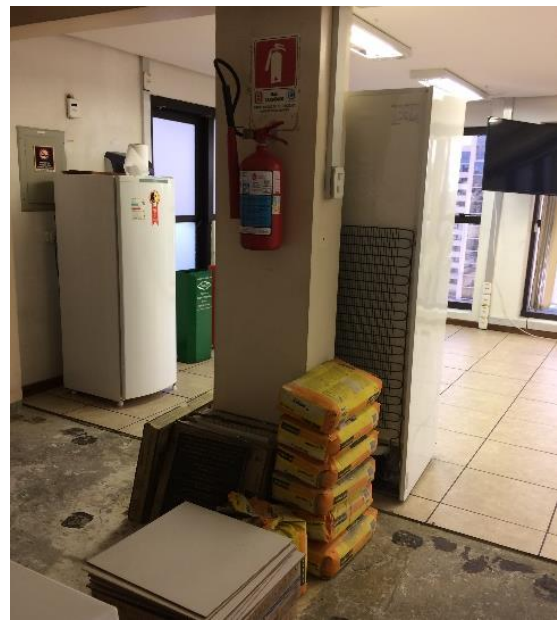

Figura 15: Obstrução de acesso ao extintor.

\subsection{Planilha do Método GUT}

Com base nas anomalias e falhas encontradas elaborou-se a matriz GUT, método amplamente utilizado pelos engenheiros inspetores prediais, que relaciona gravidade, urgência e tendência através da multiplicação de pesos estabelecidos a estes fatores, que são atribuídos para obter-se a prioridade das anomalias e falhas encontradas e assim indicar quais as intervenções deverão ser realizadas com maior celeridade. Na tabela 5, é apresentada planilha com a matriz GUT e os pesos atribuídos para gravidade, urgência e tendência de cada anomalia/falha.

Tabela 5 - Matriz GUT com os pesos atribuídos

\begin{tabular}{l|c|c|c|c|c}
\hline Anomalia/Falha & Gravidade & Urgência & Tendência & Produto & Prioridade \\
\hline Formação de fissuras & 6 & 6 & 6 & 216 & 4 \\
\hline Armadura exposta & 8 & 6 & 6 & 288 & 3 \\
\hline Deterioração de materiais, destacamento, desagregação & 6 & 3 & 3 & 54 & 5 \\
\hline Eflorescência, desenvolvimento de organismos biológico (laje) & 3 & 3 & 3 & 27 & 6 \\
\hline Infiltrações & 8 & 10 & 10 & 800 & 1 \\
\hline Degradação/desgaste do material & 3 & 3 & 3 & 27 & 6 \\
\hline Falha na sinalização & 3 & 3 & 3 & 27 & 6 \\
\hline Obstrução de acesso & 8 & 8 & 8 & 512 & 2 \\
\hline Eflorescência, desenvolvimento de organismos biológico (paredes) & 3 & 3 & 3 & 27 & 6 \\
\hline Deterioração dos materiais, destacamento, empolamento, pulverulência & 3 & 3 & 3 & 27 & 6 \\
\hline Desagregação de elementos, partes soltas, partes quebradas & 3 & 2 & 2 & 12 & 7 \\
\hline
\end{tabular}

\subsection{Planilhas do Método FMEA}

Foram atribuídas notas para severidade, ocorrência e detecção para as anomalias e falhas observadas e após, calculado o produto de severidade*ocorrência*detecção, resultado no número de prioridade de risco (NPR).

O método FMEA, objetiva levar em consideração o que ocasionou a manifestação observada, pois FMEA baseia-se na detecção da falha antes da sua ocorrência, sendo uma ferramenta de grande utilidade para elaboração de inspeções periódicas, que auxiliam nas manutenções preventivas, pois ao se analisar os modos de falha potenciais, poderia evitar o efeito de falha, neste caso apresentado através das manifestações patológicas e falhas encontradas. Na tabela 6, é apresentada planilha do método FMEA e os pesos atribuídos para severidade, ocorrência e detecção de cada anomalia/falha. Também foram identificados, conforme demonstra a Tabela 6 as percepções sobre os modos de falha potenciais, efeitos potenciais de falhas e causas potenciais de falha. 
Tabela 6 - Matriz FEMEA com os pesos atribuídos

\begin{tabular}{l|c|c|c|c|c}
\hline Anomalia/Falha & Severidade & Ocorrência & Detecção & Produto & NPR \\
\hline Formação de fissuras & 9 & 10 & 5 & 450 & 1 \\
\hline Armadura exposta & 9 & 10 & 5 & 450 & 1 \\
\hline Deterioração de materiais, destacamento, desagregação & 8 & 8 & 5 & 320 & 3 \\
\hline Eflorescência, desenvolvimento de organismos biológicos (laje) & 6 & 6 & 4 & 144 & 5 \\
\hline Infiltrações & 9 & 10 & 4 & 360 & 2 \\
\hline Degradação/desgaste do material (antiderrapante) & 5 & 3 & 4 & 60 & 7 \\
\hline Falha na sinalização & 6 & 3 & 4 & 72 & 6 \\
\hline Obstrução de acesso & 9 & 6 & 4 & 216 & 4 \\
\hline Eflorescência, desenvolvimento de organismos biológicos (paredes) & 6 & 6 & 4 & 144 & 5 \\
\hline Deterioração dos materiais, destacamento, empolamento, pulverulência & 4 & 3 & 4 & 48 & 8 \\
\hline Desagregação de elementos, partes soltas, partes quebradas & 6 & 3 & 4 & 72 & 6 \\
\hline
\end{tabular}

\subsection{Análise dos resultados}

Na comparação entre os métodos utilizados para a classificação da ordem de prioridades obtidos pelos métodos GUT e FMEA, observou-se que umas das diferenças entre eles é que GUT avalia a existência de riscos aos usuários, e no aspecto da urgência, se aquele evento já está em ocorrência e qual a sua evolução. A determinação destes parâmetros envolve bastante expertise do engenheiro que a está realizando e não leva em consideração a determinação de maneiras de evitarem-se falhas futuras. Conforme observado nas pesquisas realizadas, é a ferramenta mais utilizada pelos inspetores prediais, devido a sua praticidade na determinação das prioridades. O método FMEA preocupa-se em avaliar de onde vem a falha, sua origem e como o sistema pode vir a falhar, sendo uma análise mais técnica, de forma a obter-se resultados mais completos nas inspeções, objetiva diminuir a subjetividade da classificação dos riscos, porém se mostra mais eficiente quando utilizada por uma equipe que avaliará em conjunto os parâmetros. O método FMEA envolve estudo mais aprofundado das falhas e dispensa mais tempo, se mostra uma ferramenta muito interessante de ser aprofundada para estudo dos modos de falha e seus efeitos, podendo ser aplicada em vários segmentos da engenharia civil. O método FMEA é melhor aproveitado quando utilizado para rotinas de inspeções preventivas, de forma a identificar os modos de falha potenciais dos sistemas.

As diferenças entre as interações resultantes dos dois métodos se dão pelo fato de que a matriz GUT indicou quais itens apresentam uma maior gravidade, o que indica que estes deverão ser priorizados para reparos, enquanto que os do FMEA, apesar de no item severidade equiparar-se a gravidade, os itens ocorrência e deteç̧ão referem-se respectivamente a probabilidade de parar o sistema e se a falha é detectada antes que aconteça. O método GUT indicou como o item infiltrações a maior prioridade de reparos e no método FMEA, a causa potencial de falha mais incidente foram as infiltrações, que fazem com que ocorram os efeitos (consequências da falha).

Para a inspeção realizada, o método GUT mostrou-se mais eficiente, no sentido da priorização dos reparos, pois as manifestações já estão em ocorrência e a utilização do FMEA neste caso, auxiliaria na prevenção de ocorrência de problemas em outros locais, baseado na detecção das causas das falhas observadas.

\section{CONSIDERAÇÕES FINAIS}

A Inspeção Predial é uma importante ferramenta de prevenção e acompanhamento dos desgastes que ocorrem nas edificações com o decorrer do tempo, sua importância também se dá no sentido de identificar e acompanhar a ocorrência de anomalias e falhas que possam surgir, e neste caso, indicar ações corretivas e preventivas nos sistemas. A Inspeção Predial também tem sua importância relacionada com a implantação do plano de manutenções preventivas ou corretivas, conforme preconiza a NBR 5674 (ABNT, 2012).

Com a utilização da Norma de Inspeção Predial do IBAPE, aliada as ferramentas de gerenciamento de riscos dos métodos GUT e FMEA, foi possível apurar a ordem de prioridades das correções necessárias nos sistemas que apresentaram problemas. Os resultados demonstraram que a maioria das falhas que puderam ser observadas na vistoria, são os decorrentes de problemas de umidade advindas dos pavimentos superiores aos das manifestações patológicas. Com a realização de Inspeções periódicas, as incorreções poderiam ser identificadas antes de iniciar o aparecimento destas 
manifestações, desta forma prevenindo seu surgimento. A escolha de um método técnico como os apresentados neste trabalho são de extrema importância para a correta classificação e priorização das correções necessárias.

\section{REFERÊNCIAS}

ANGELONI, Bruna Possamai Della Angeloni; ZANCAN, Evelise Chemale. Inspeção predial tridimensional das casas populares do município de Jacinto Machado, SC: Estudo de Caso. Artigo (Curso de Engenharia Civil) Universidade do Extremo Sul Catarinense - UNESC. Criciúma - SC, 2011.

ASSOCIAÇÃO BRASILEIRA DE NORMAS TÉCNICAS. NBR 14037. Diretrizes para elaboração de manuais de uso, operação e manutenção das edificações - Requisitos para elaboração e apresentação dos conteúdos. Rio de Janeiro, 2014.

ASSOCIAÇÃO BRASILEIRA DE NORMAS TÉCNICAS. NBR 5674. Manutenção de edificações - Requisitos para o sistema de gestão da manutenção. Rio de Janeiro, 2012.

ASSOCIAÇÃO BRASILEIRA DE NORMAS TÉCNICAS. NBR 15575. Edificações Habitacionais: desempenho. Rio de Janeiro, 2013.

COSTA, Anderson dos Santos; ZANCAN, Evelize Chemale. Inspeção Predial: Estudo de caso de um edifício residencial. Artigo (Curso de Engenharia Civil) Universidade do Extremo Sul Catarinense - UNESC. Criciúma - SC, 2012.

GOMIDE, Tito Lívio Ferreira; PUJADAS, Flávia Zoéga Andreatta; FAGUNDES NETO, Jerônimo Cabral Pereira. Técnicas de inspeção e manutenção predial. São Paulo: PINI, 2006. 227p.

GOMIDE, Tito Lívio Ferreira; FAGUNDES NETO, Jerônimo Cabral Pereira; GULLO, Marco Antonio. Inspeção Predial Total, diretrizes e laudos no enfoque da qualidade total e da engenharia diagnóstica. São Paulo: PINI, 2011. $145 \mathrm{p}$.

GOMIDE, Tito Lívio Ferreira; FAGUNDES NETO, Jerônimo Cabral Pereira; GULLO, Marco Antonio. Normas técnicas para engenharia diagnóstica em edificações. São Paulo: PINI, 2009. 248P.

INSTITUTO BRASILEIRO DE AVALIAÇÕES E PERÍCIAS DE ENGENHARIA - IBAPE. Norma de inspeção predial nacional. Aprovada em assembleia nacional de 25 out. 2012.

INSTITUTO BRASILEIRO DE AVALIAÇÕES E PERÍCIAS DE ENGENHARIA - IBAPE. Inspeção Predial a Saúde dos Edifícios. Câmara de Inspeção Predial do IBAPE/SP. São Paulo, 2012.

KALIL, Marli. L.; LARA, Alexandre Marcelo Fontes. Aplicação de ferramentas de confiabilidade na atividade de inspeção predial. Disponível em: 〈http://www.mrcl.com.br/xivcobreap/tt23.pdf> Acesso em: 02. mai. 2017.

NASCIMENTO, Flávia; VAZQUEZ, Elaine. A Inspeção Predial como ferramenta de recuperação e manutenção das edificações. Artigo, IV CIRMARE - Congresso Internacional na "Recuperação, Manutenção e Restauração de Edifícios". Rio de Janeiro - RJ, 2015.

NEVES, Daniel Rodrigues Rezende Neves; BRANCO, Luiz Antônio M. N. Estratégia de Inspeção Predial. Artigo, Construindo, Belo Horizonte, Volume 1, Número 2, p.12-19, jul./dez. 2009.

PINHEIRO, Rafael Luiz Ochoa. Inspeção Predial dos blocos XXI da UNESC: Estudo de caso. 2010. 112p. Trabalho de Conclusão de Curso - Curso de Engenharia Civil da Universidade do Extremo Sul Catarinense, UNESC, Criciúma, $\mathrm{SC}$.

PUJADAS, Flávia Zoéga Andreatta. Inspeção Predial: ferramenta de avaliação da manutenção. Disponível em: <http://ibape-nacional.com.br/biblioteca/wp-content/uploads/2013/02/Inspecao-Predial-Ferramenta-de-Avaliacao-daManutencao.pdf.> Acesso em: 17. abr. 2017.

SILVA, Severino Virgílio; MONTEIRO Eliana Cristina Barreto. Aplicação das ferramentas da qualidade FMEA e FTA para detecção e controle de patologias em estruturas de concreto armado do Aeroporto Internacional do Recife. Artigo, Revista de Engenharia e Pesquisa Aplicada, Volume 1, Número 1, 2016.

SILVA, Wladson Livramento. Inspeção Predial: diretrizes, roteiro e modelo de laudo para inspeções em edificações residenciais da cidade do Rio de Janeiro. 2016, 138p. Projeto de Graduação - Curso de Engenharia Civil da Universidade Federal do Rio de Janeiro, UFRJ, Rio de Janeiro, RJ.

THOMPSON JUNIOR, Werinton Luiz; ZANCAN, Evelise Chemale. Inspeção Predial com levantamento dos custos para reparação das patologias construtivas: Caso de cinco creches municipais em Içara-SC. Artigo (Curso de Engenharia Civil) Universidade do Extremo Sul Catarinense - UNESC. Criciúma - SC, 2011.

VERZOLA, Simone Nunes; MARCHIORI, Fernanda Fernandes; ARAGON, José Octávio. Proposta de lista de verificações para inspeção predial $x$ urgência das manutenções. Artigo, XV Encontro Nacional de Tecnologia do Ambiente Construído. Maceió - AL, 2014. 